\title{
ANTIULCER ACTIVITY OF ETHANOLIC EXTRACT OF BAUHINIA TOMENTOSA LINN. LEAVES
}

\author{
M.Shantha* ${ }^{*}$ R.Senthamarai ${ }^{1}$, T.Shri Vijaya Kirubha ${ }^{2}$ \\ Department of Pharmacognosy \\ Periyar College of Pharamaceutical Sciences, Tiruchirappalli-620021, Tamil Nadu. \\ shantha.cog@gmail.com
}

\begin{abstract}
:
The leaves of Bauhinia tomentosa Linn are used traditionally in the treatment of gastric ulcer. The present study was carried out to determine the effect of ethanolic extract of Bauhinia tomentosa Linn. Leaves for antiulcer effect in pylorus ligated rats. The extract showed antiulcer activity by pyloric ligated model in albino rats. The results revealed significant reduction is total acidity and the ulceration.
\end{abstract}

Keywords: Bauhinia tomentosa Linn, Flavonoids, Saponins, Pylorus ligation, Gastric ulcer, Famotidine.

\section{INTRODUCTION}

Several plants are being screened for their varied pharmacological activities. Bauhinia tomentosa Linn.(Caesalpiniaceae), commonly known as Iruvaji or Kokkumandari in Tamil and Adadim-andaram in Telugu is distributed throughout India.Leaves broader than long, coriaceous, pubescent below flowers with a distinct odour, usually axillary pendent and half open, yellow with a maroon dot at the base of the centre petal pods distinctly, stacked, glabrous, 6-10 seeded. The stem bark have been traditionally used as astringent gargle, the dried leaves, buds and flowers are used in dysentry. The flowers and fruits contains isoquecitrin, quercetin and rutin. The fruits and seeds are used as diuretic and the literature survey clearly shows that the Bauhinia tomentosa Linn has been traditionally used as a medicinal plant with hepato protective, antioxidant, diuretic and astringent, antiulcer, anti- pyretic properties. Review of literature did not reveal any information on the anti-ulcer activity. So the present study was aimed to investigate the anti-ulcer activity of the ethanolic extract of leaves of Bauhinia tomentosa Linn against pylorus induced ulcer model.

\section{MATERIALS AND METHODS}

\section{Preparation of Test Extract}

The leaves of Bauhinia tomentosa Linn. was collected from foot hill of Vorrezeraud, Salem (Tamil Nadu) and authenticated. Washed leaves were air dried and powdered. About $500 \mathrm{gm}$ of powdered leaves were defatted with petroleum ether $\left(60-80^{\circ}\right)$ for $3-4$ days and extracted exhaustively with ethanol using soxhlet apparatus. The extracts obtained were made solvent free by distillation. The above extracts were used for anti-ulcer activity studies. 


\section{Phytochemical Screening}

Qualitative chemical tests were employed in screening the extracts for different constituents for detecting the presence of alkaloids, saponins, tannins, flavanoids etc.

\section{Animals}

The albino rats weighing between 100-150gm of either sex and approximate same age used in the present studies were procured from Sri Venkateswara Enterprises, Bangalore, India.Ethical clearence was obtained from the Institutional Animal Ethics committee prior to the experiment.

\section{Housing Condition}

The animals were housed 3 per cage in polypropylene cage and were moved to experimental room where they are allowed to acclimatize for a day before treatment. The environmental conditions of the animal room were as per a specific design. A $10 \%$ air exhaust in the air conditioning unit was maintained along with a relative humidity of $60 \pm 5 \% \mathrm{RH}$ and a temperature of $25 \pm 3^{\circ} \mathrm{c}$ was stabilized. A $12 \mathrm{hr}$ light dark cycle was also regulated for the experimental animals. The animals were acclimatized to the laboratory condition for 1 week before starting the experiment. The animals were fasted for atleast 12 hours before the onset of each activity.

\section{Ulcer Induction Procedure}

The drugs were given orally by making suspension with acacia 2 hours prior to pylorus ligation which was carried out according to technique reported by (Shay et al, S.K. Kulkarni). Group I received acacia suspension $(\mathrm{mg} / \mathrm{Kg})$ acted as a control Group II received Famotidine $(10 \mathrm{mg} / \mathrm{Kg})$ acted as standard, Group III and Group IV received ethanolic extract of leaves of Bauhinia tomentosa $\mathrm{Linn}(200 \mathrm{mg} / \mathrm{Kg}, 400 \mathrm{mg} / \mathrm{Kg})$ respectively.

\section{Pylorus Ligated Induced Ulcer}

Pylorus ligation procedure was used to induce peptic ulcers. The animals were subjected to pylorus ligation. They were sacrified 6 hours after pyloric ligation to observe gastric lesions. The gastric juice was collected, centrifuged and subjected to chemical analysis. The gastric ulcer was measured and the ulcer index was determined. (Under light ether anesthesia, the abdomen was opened by giving midline incision of $1 \mathrm{~cm}$ long below xephoid process, pyloric portion of the stomach below the liver) was slightly lifted out and the thread was passed around the pyloric sphincter and a tight knot was applied, precautions was taken to avoid traction to the pylorus or damage its blood supply. Abdominal wall was closed by interrupted sutures. Drug treatment was done before 45 minutes of pylorus ligation. The animal was deprived of both food and water during post operative period. After $4 \mathrm{hrs}$ the stomach were dissected out and the mucosal layer of the stomach was observed under a magnifying lens and was checked for ulcer. The ulcer index was determined as described below:

Ulcer index $=10 / X$ (where, $X=$ total area of stomach mucosa / total ulcerated area). 


\section{Collection of Gastric Juice}

Gastric juice was collected from pylorus ligated in rats. The gastric juice thus collected was centrifuged and the volume of gastric juice as well as $\mathrm{pH}$ of gastric juice was noted. The gastric juice was subjected to biochemical estimations as follows.

\section{Determination of Free And Total Acidity}

One $\mathrm{ml}$ of gastric juice was pipetted into a $100 \mathrm{~m} 1$ conical flask, added 2 or 3 drops of Topfers reagent and titrated with $0.01 \mathrm{~N}$ Sodium hydroxide until all traces of red colour disappeared and the colour of the solution was yellowish orange. The volume of alkali added was noted. This volume corresponds to free acidity. 2 or 3 drops of phenolphthalein solution was added and titration was continued until a definite red tinge appears. Again the total volume of alkali added was noted. The volume corresponds to total acidity. The data concerning the $\mathrm{pH}$, acid secretion and ulcer index were analyzed by student ' $\mathrm{t}$ ' test were show in table No.1, and Graph No 1,2,3.

\section{Acidity was calculated by using formula:}

Acidity $(\mathbf{m e q} / \mathbf{L} / \mathbf{1 0 0 g})=$ Volume of $\mathrm{NaOH} \times$ Normality of $\mathrm{NaOH} \times 100 / 0.1$

\section{Effect of ethanolic extracts of leaves of Bauhinia tomentosa in Gastric pH}

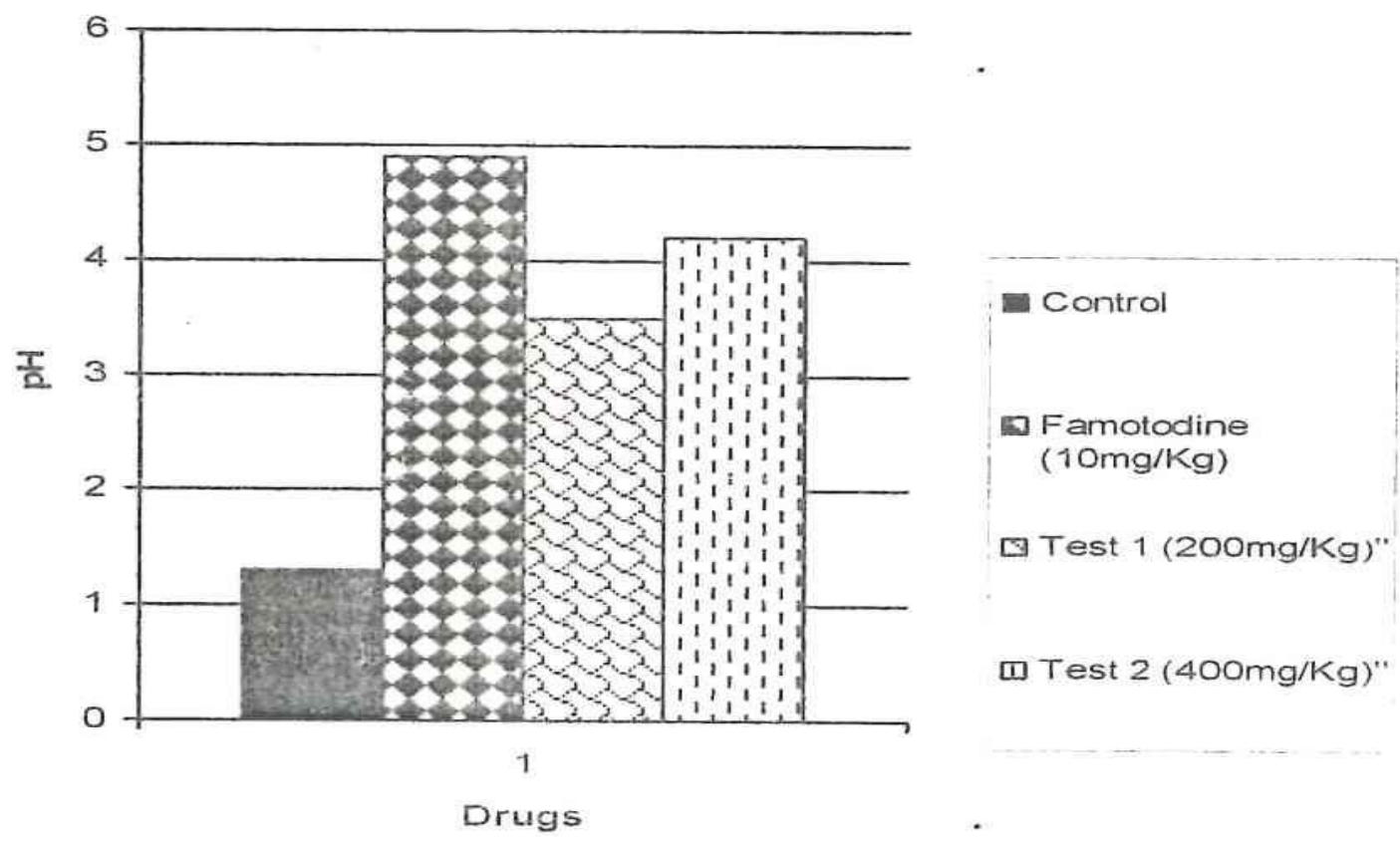


Effect of ethanolic extract of leaves of Bauhinia tomentosa in free acid
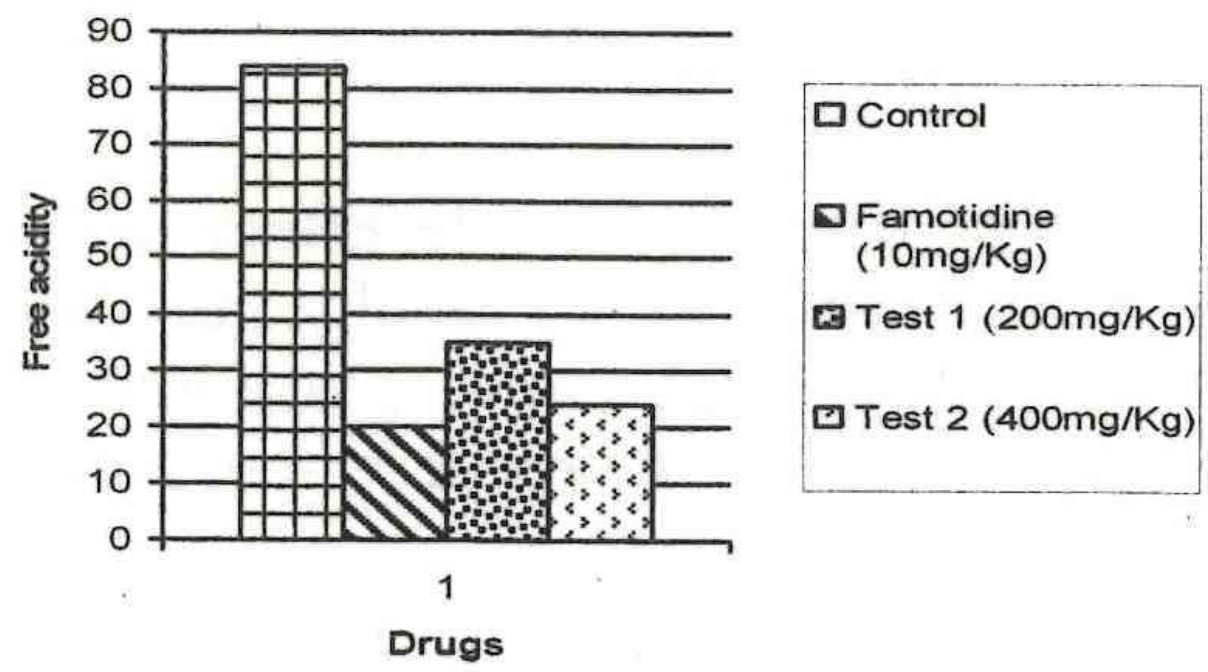

Graph: 2

Effect of ethanolic extract of leaves of Bauhinia tomentosa in Ulcer index

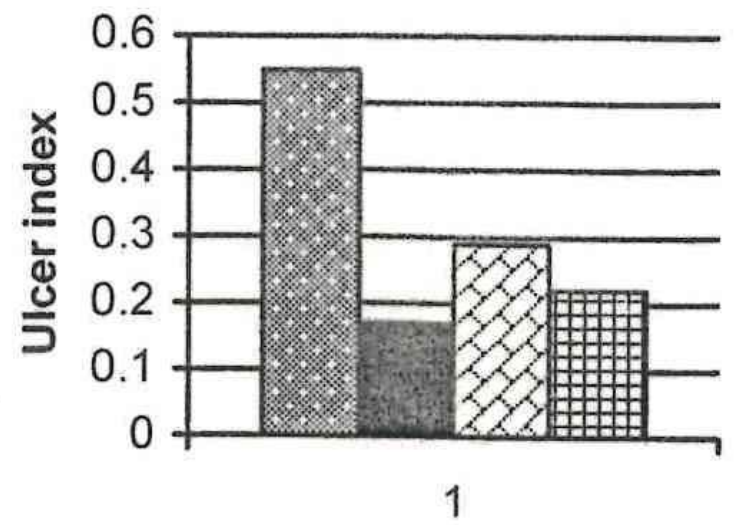

Drugs

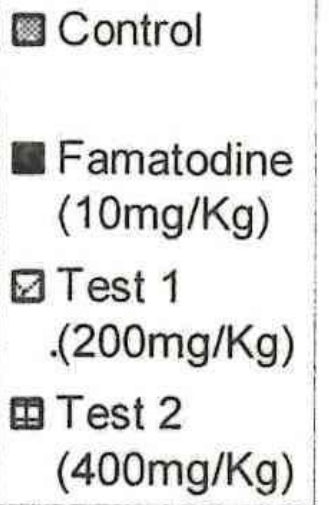
$(400 \mathrm{mg} / \mathrm{Kg})$

Graph: 3 


\section{RESULTS}

The ethanolic extract of Leaves of Bauhinia tomentosa Linn. was tested for anti-ulcer activity and it was compared with standard famotodine, it showed significant anti-ulcer activity, the reduction in gastric acidity and ulceration may be due to histaminergic mechanism by $\mathrm{H} 2$ receptor blockade.

Table 1. Effect of Ethanolic Extract of Leaves of Bauhinia tomentosa Linn.

\begin{tabular}{|c|c|l|c|c|c|}
\hline S.No & Group & $\mathbf{p H}$ & $\begin{array}{c}\text { Total acidity } \\
(\mathbf{m E q} / \mathbf{L})\end{array}$ & $\begin{array}{c}\text { Free acidity } \\
(\mathbf{m E q} / \mathbf{L})\end{array}$ & Ulcer Index \\
\hline 1 & Control (acacia 1mg/Kg) & $1.3 \pm 0.06$ & $94 \pm 5.2$ & $84 \pm 4.6$ & $0.55 \pm 0.06$ \\
\hline 2 & $\begin{array}{c}\text { Standard (Famotodine } \\
10 \mathrm{mg} / \mathrm{Kg})\end{array}$ & $4.9 \pm 0.08^{*}$ & $32 \pm 2.6^{*}$ & $20 \pm 1.46$ & $0.17 \pm 0.04$ \\
\hline 3 & $\begin{array}{c}\text { Ethanolic extract of } \\
\text { leaves of } \\
\text { Bauhiniatomentosa } \\
\text { Linn(200mg/Kg) }\end{array}$ & $3.5 \pm 0.07^{* *}$ & $48 \pm 3.32^{* *}$ & $35 \pm 1.3$ & $0.29 \pm 0.05$ \\
\hline 4 & $\begin{array}{c}\text { Ethanolic extract of } \\
\text { leaves of Bauhinia } \\
\text { tomentosa }\end{array}$ & $4.2 \pm 0.06^{* * *}$ & $36 \pm 2.4^{* * *}$ & $24 \pm 1.1$ & $0.22 \pm 0.05$ \\
& Linn(400mg/Kg) & & & & \\
\hline
\end{tabular}

$\mathrm{n}=6$. Values are expressed as \pm S.E.M.

$\mathrm{P} * * *<0.000 \mathrm{P}^{* *}<0.01 \mathrm{P} *<0.05$

\section{CONCLUSION}

Based on the traditional uses, the plant was selected. The phytochemical and pharmacological studies were done on leaves of Bauhinia tomentosa Linn. The leaves of the plant were separated, dried under shade and subjected for phytochemical studies.The phytochemical constituents were extracted exhaustively with ethanol using soxhlet apparatus. Qualitative chemical tests were employed in screening the extracts for different constituents. Conventional protocol for detecting the presence of alkaloids, saponins, tannins, flavanoids etc. were utilized. The ethanolic extract of leaves of Bauhinia tomentosa Linn.showed the presence of many phytoconstituents such as carbohydrates, Glycosides,Phytosterols, Fixed oils and fats,Saponins,Flavanoids, Gums and Mucilage.Hence Ethanol extract was selected for the Pharmacological studies.

In the Pharmacological studies ethanolic extract of leaves of Bauhinia tomentosa Linn.showed significant anti-ulcer activity.

The anti-ulcer activity was evaluated by using pylorus ligated induced ulcer model in rats.Present study supports the leaves of Bauhinia tomentosa Linn. posses good anti-ulcer activity. 


\section{ACKNOWLEDGEMENT}

I express my heartful and profound thanks to our Honorable Management of Periyar College of Pharmaceutical Sciences, Tiruchirappalli - 620021, TamilNadu.

\section{REFERENCES}

[1] The Wealth of India ; A Dictionary of Indian Materials and Industrial Products, CS $R$ Hillside Road,

New Delhi-110012, volume II, B April 26, (1998) 53.

[2] Dr. Kokate C.K., Practical Pharmacognosy published by M.K. Jain for Vallabh Prakashan AP-53A, Pitampura,

Delhi-110 088, Fourth edition (2003) 107.

[3] Trease, G.E., Evans, M.C. Text book of pharmacognosy, $12^{\text {th }}$ edition. Balliere, Tindall, London, (1983) 343-383.

[4] Shay, H., Kamorrow, S.A., Fele, S.S., Merayl, D., Cirulenterri, H., and Siplet, H (1945) A simple method of the uniform

production of gastric ulceration Gastroenterilogy,(1945) 5, 43.

[5] Ghosh M.N. (2005). Fundamentals of experimental pharmacology; published by S.K.

Ghosh \& others 109, College

Street, Kolkata 700102; $3^{\text {rd }}$ edition (2005) 180.

[6] Gupta, m.B., Nath, R. Gupta and Bhargara, K.P. (1983). A study of the Antiulcer activity of diarepame and other

tranquillosedatives in albinorats, clinical and experimental pharmacology, (1983) 12, 61.

[7] Kulakarni S.K., Hand Book of Experimental pharmachology, publ-ished by M.K. Jani for Vallabh Prakashan; $S U-$

221, Pitampura, Delhi - 110 034, 3td edition (2005) 148-150.

[8] Renisford K.D. side effect of anti-inflammatory / analgesic drugs, epidemiology and gastrointestinal tract. Tends

pharmaceutics, (1984) 5, 156-159.

[9] Kulkarni S.K., Hand Book of Experimental Pharmacology, publ-ished by M.K.Jain for vallabh prakashan; $S U$ - 221,

Pitampura, Delhi - 110 034, $3^{\text {rd }}$ edition (2007) 149.

[10] Ghosh, M.N. Statistical analysis,In Fundamentals of experimental pharmacology, published by S.K. Ghosh \& others

109, J. Simla (Ed), Calcutta scientifica Book Agency, (1984) 177,182.

[11] Broidie, D.S ,Treatment with Histamine $\mathrm{H}_{2}$ receptors antagonist in cases of gastric ulcer, (1966) 231-241. 